\title{
Dietary Linoleic Acid and Its 0xidized Metabolites Exacerbate Liver Injury Caused by Ethanol via Induction of Hepatic Proinflammatory Response in Mice
}

Dennis R. Warner, ${ }^{*}$ Huilin Liu, ${ }^{\dagger}{ }^{\dagger}$ Matthew E. Miller, ${ }^{*}$ Christopher E. Ramsden, ${ }^{\ddagger \S}$ Bin Gao, ${ }^{\ddagger}$ Ariel E. Feldstein, ${ }^{\natural}$ Susanne Schuster, ${ }^{\text {व }}$ Craig J. McClain, ${ }^{* \| * * \dagger \dagger \neq}$ and Irina A. Kirpich ${ }^{* \| \dagger \dagger \dagger \ddagger}$

From the Division of Gastroenterology, Hepatology, and Nutrition, * Department of Medicine, the Department of Pharmacology and Toxicology," the Hepatobiology and Toxicology Program, ${ }^{\dagger \dagger}$ and the University of Louisville Alcohol Research Center ${ }^{\ddagger \ddagger}$ University of Louisville School of Medicine, Louisville, Kentucky; the College of Life Science, ${ }^{\dagger}$ Jilin University, Changchun, China; the National Institute on Alcohol Abuse and Alcoholism, ${ }^{\ddagger}$ Bethesda, Maryland; the National Institute on Aging, ${ }^{\S}$ Baltimore, Maryland; the Division of Gastroenterology, "Department of Pediatrics, University of California San Diego, San Diego, California; and the Robley Rex Veterans Medical Center, ** Louisville, Kentucky

Accepted for publication June 22, 2017.

Address correspondence to Irina A. Kirpich, Ph.D., M.P.H., Division of Gastroenterology, Hepatology, and Nutrition, Department of Medicine, University of Louisville, 505 Hancock St, Louisville, KY 40202. E-mail: i0kirp01@ louisville.edu.

\begin{abstract}
Alcoholic liver disease is a major human health problem leading to significant morbidity and mortality in the United States and worldwide. Dietary fat plays an important role in alcoholic liver disease pathogenesis. Herein, we tested the hypothesis that a combination of ethanol and a diet rich in linoleic acid (LA) leads to the increased production of oxidized LA metabolites (OXLAMS), specifically 9- and 13hydroxyoctadecadienoic acids (HODEs), which contribute to a hepatic proinflammatory response exacerbating liver injury. Mice were fed unsaturated (with a high LA content) or saturated fat diets (USF and SF, respectively) with or without ethanol for 10 days, followed by a single binge of ethanol. Compared to SF+ethanol, mice fed USF+ethanol had elevated plasma alanine transaminase levels, enhanced hepatic steatosis, oxidative stress, and inflammation. Plasma and liver levels of 9- and 13-HODEs were increased in response to USF+ethanol feeding. We demonstrated that primarily $9-\mathrm{HODE}$, but not $13-\mathrm{HODE}$, induced the expression of several proinflammatory cytokines in vitro in RAW264.7 macrophages. Finally, deficiency of arachidonate 15-lipoxygenase, a major enzyme involved in LA oxidation and OXLAM production, attenuated liver injury and inflammation caused by USF+ethanol feeding but had no effect on hepatic steatosis. This study demonstrates that OXLAM-mediated induction of a proinflammatory response in macrophages is one of the potential mechanisms underlying the progression from alcohol-induced steatosis to alcoholic steatohepatitis. (Am J Pathol 2017, 187: 2232-2245; http://dx.doi.org/10.1016/j.ajpath.2017.06.008)
\end{abstract}

Alcohol-associated health problems, including alcoholic liver disease (ALD), are major global health problems. ALD progresses through the course of several pathologies, including steatosis, alcoholic hepatitis, cirrhosis, and potentially hepatocellular carcinoma. Alcoholic hepatitis occurs in approximately $10 \%$ to $35 \%$ of chronic heavy drinkers, and severe alcoholic hepatitis accounts for significant morbidity and mortality, approaching $35 \%$ to $45 \%$. Approximately $10 \%$ to $20 \%$ of heavy drinkers will eventually develop cirrhosis. ${ }^{2,3}$ The specific mechanisms responsible for ALD development and progression are not fully understood, and there is no Federal Drug Administration-approved therapy for any stage of ALD.
Supported by NIH grants R21 AA020849-01A1 (I.A.K.), R01 AA024102-01A1 (I.A.K.), U01AA022489 (A.E.F. and C.J.M.), 1U01AA021901-01 (C.J.M.), 1U01AA021893-01 (C.J.M.), and R01AA023681 (C.J.M.); the Department of Veterans Affairs grant I01BX000350 (C.J.M.); the Department of Defense grant W81XWH-11-10595 (C.J.M.); the National Institute on Alcohol Abuse and Alcoholism and National Institute on Aging Intramural Programs (C.E.R.); the National Institute of General Medical Sciences of the NIH Institutional Development Award under grant P20GM113226 (C.J.M.); the NIH National Institute on Alcohol Abuse and Alcoholism under award P50AA024337 (C.J.M.); and the National Center for Research Resources, NIH grant S10RR027926 (Wayne State Lipidomics Core Facility).

D.R.W. and H.L. contributed equally to this work.

Disclosures: None declared. 
The link between diet, specifically dietary fat, and alcohol consumption in ALD pathogenesis has been increasingly appreciated. Findings from an epidemiological study that analyzed dietary fat intake in individuals from countries with similar per capita alcohol consumption revealed that intake of saturated fat (SF) was associated with lower mortality rates, whereas dietary intake of unsaturated fat (USF) was associated with a higher mortality from alcoholic cirrhosis. ${ }^{4}$ The beneficial effects of dietary SF (predominantly rich in medium- or long-chain saturated fatty acids) and the damaging effects of dietary USF [primarily enriched in linoleic acid (LA), an $\omega-6$ polyunsaturated fatty acid (PUFA)] on alcoholinduced liver injury have been demonstrated in numerous preclinical studies using rodent models of ALD. ${ }^{5-9}$ LA is required for the development of experimental ALD, with the severity of liver pathology correlating to the amount of LA in the diet. ${ }^{10}$ On a mechanistic level, the deleterious effects of USF in comparison to the protective effects of SF are thought to result from alterations in hepatic lipid homeostasis,, $11-14$ induction of hepatic lipid peroxidation and oxidative stress, ${ }^{6,15}$ changes in the gut microbiota, impaired intestinal barrier integrity, and elevated endotoxemia with subsequent hepatic macrophage activation and increased production of hepatic proinflammatory cytokines. ${ }^{7,8,16,17}$ LA is the most abundant $\omega-6$ PUFA in human diets and in human plasma and membrane lipids. ${ }^{18}$ The consumption of LA, which has dramatically increased during the past several decades, ${ }^{19}$ is positively correlated with increasing prevalence of several pathological conditions, including obesity. ${ }^{20}$ LA can be enzymatically converted to bioactive oxidized LA metabolites (OXLAMs), primarily via the actions of cellular lipoxygenases [arachidonate 15-lipoxygenase (ALOX15) and ALOX15B in humans, and ALOX15 (12/15-LO) in rodents] or nonenzymatically via free radical-mediated oxidation in response to oxidative stress. OXLAMs are involved in various intracellular signaling pathways and may induce a proinflammatory response in different cell types. ${ }^{21-23}$ OXLAMs play a role in the development of different pathological conditions, such as inflammatory hyperalgesia and the metabolic syndrome. ${ }^{24,25}$ OXLAMs, specifically 9- and 13hydroxyoctadecadienoic acids (9- and 13-HODEs, respectively), were elevated in patients with nonalcoholic fatty liver disease, ${ }^{26}$ and a decrease in plasma OXLAM levels was correlated with hepatic histological improvement in these patients. ${ }^{27}$ Increased levels of 9- and 13-HODEs were found in patients with alcoholic liver cirrhosis in parallel with the induction of hepatic ALOX15 and ALOX15B. ${ }^{28}$ Elevated 9and 13-HODE levels were also observed in experimental rodent models of ALD and were associated with ethanolinduced liver injury, steatosis, and inflammation. ${ }^{29,30}$ Based on these observations, we hypothesized that OXLAMs may play a pathogenic role in ALD development and/or progression; however, the underlying mechanisms remain to be determined.

In the present study, we tested the hypothesis that the combination of ethanol and a diet with a high content of LA contributes to and exacerbates ethanol-induced liver injury through increased OXLAM production and OXLAMmediated induction of hepatic proinflammatory responses. We postulated that both increased substrate availability (LA-rich dietary fat) and activation of metabolic pathways of OXLAM production, in particular the 12/15LO-mediated pathway, contribute to an ethanol-mediated increase in OXLAMs. Therefore, we further examined whether genetic ablation of Alox15 (the gene encoding 12/ 15-LO) would decrease OXLAM levels and attenuate liver injury caused by ethanol and an LA-enriched diet. For our studies, we used a chronic-binge ethanol exposure animal model of ALD (NIH National Institute on Alcohol Abuse and Alcoholism model). ${ }^{31}$ This model recapitulates the drinking pattern in humans and induces a moderately severe alcoholic liver injury with increased hepatic neutrophil infiltration, ${ }^{31}$ which is often observed in alcoholic hepatitis patients. $^{32}$

\section{Materials and Methods}

\section{Animals and Treatments}

Eight-week-old genetically unaltered wild-type (WT; C57BL/6J) and Alox15 gene knockout (B6.129S2Alox $15^{\text {tm } 11 \text { Fun }} / \mathrm{J}, 11^{\text {th }}$ backcross generation) male mice were obtained from the Jackson Laboratory (Bar Harbor, ME). Animals were housed in a specific pathogen-free barrier facility accredited by the Association for Assessment and Accreditation of Laboratory Animal Care. A 10-day ethanol feeding plus a single binge of ethanol administration was used as an experimental model of ALD (NIH National Institute on Alcohol Abuse and Alcoholism model). ${ }^{31}$ Briefly, the mice were provided free access to a LieberDeCarli control or ethanol (5\% w/v)-containing diet for 10 days. On day 11, the mice were gavaged with a single dose of ethanol solution $(20 \% \mathrm{v} / \mathrm{v})$ prepared in ultrapure water; the gavage volume was calculated to deliver $5 \mathrm{~g}$ ethanol $/ \mathrm{kg}$ body weight. The mice in control groups received an isocaloric/isovolumetric maltodextrin solution. The mice were euthanized 9 hours after the gavage. The experimental paradigm is outlined in Figure 1A. Two separate experiments were performed: WT mice were provided a USF- or SF-enriched diet with or without ethanol; and WT and Alox15 knockout mice were fed a USF-enriched diet with or without ethanol. The USF diet was supplemented with corn oil, a rich source of LA, and the SF diet was supplemented with beef tallow and medium-chain triglycerides (Research Diets, New Brunswick, NJ) (Table 1). The detailed composition of these diets has been described previously. ${ }^{33}$ In the control group, the levels of protein, carbohydrate, and fat were held constant at $17 \%, 43 \%$, and $40 \%$ of total energy, respectively. In the alcohol-containing diets, ethanol (35\% of total calories) was substituted for carbohydrate energy. The diets were prepared fresh each day, and the food consumption was monitored daily. The control groups 
A

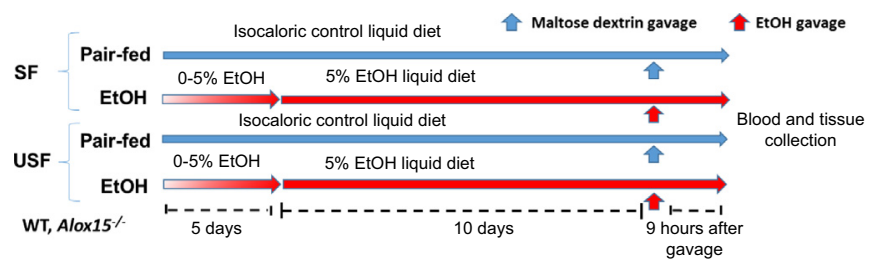

C

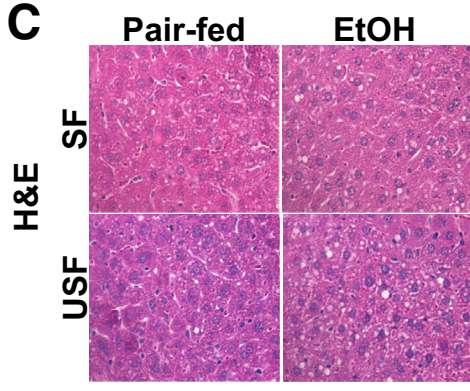

F

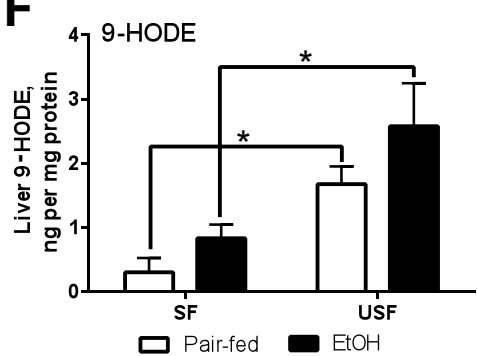

D
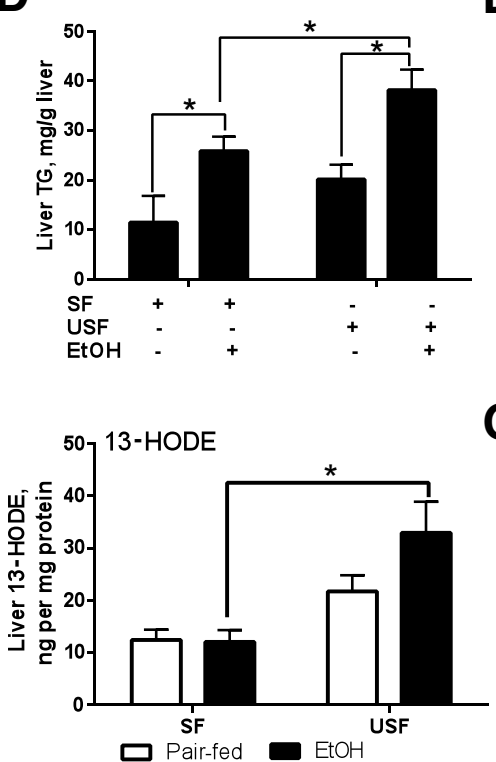

B

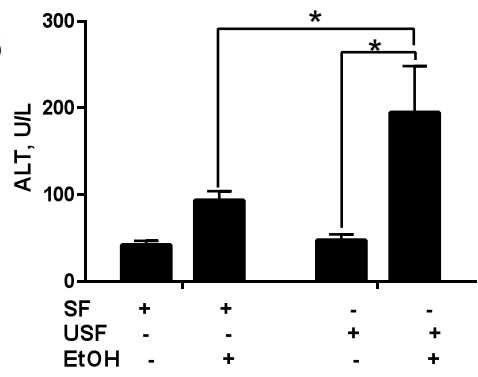

E

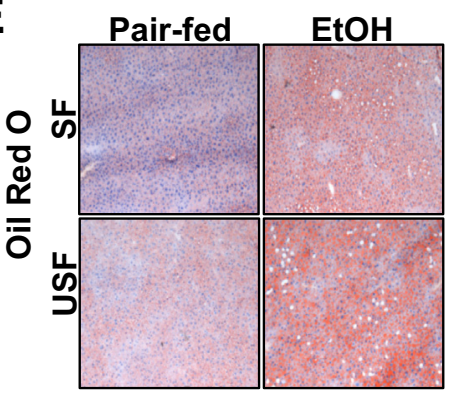

G

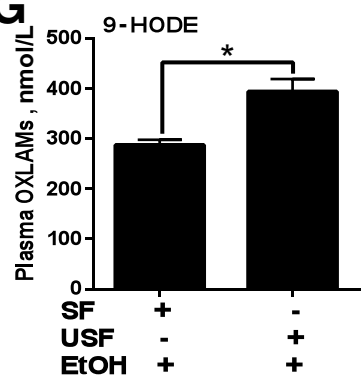

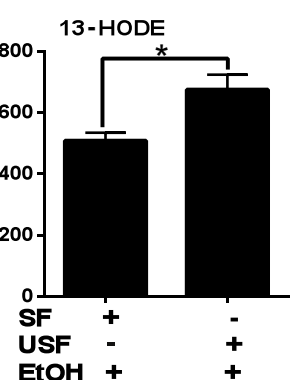

Figure 1 The experimental animal model of alcoholic liver disease. A: Schematic representation of the chronic-binge-ethanol (EtOH) exposure protocol. C57BL/J mice were fed control or ethanol diets for 10 days, followed by single gavage of maltose dextrose or ethanol, respectively. Animals were euthanized 9 hours after gavage. B: Serum ALT. C: Representative images of hepatic hematoxylin and eosin (H\&E) staining. D: Liver triglyceride (TG) levels. E: Representative images of Oil Red 0 staining. $\mathbf{F}$ and $\mathbf{G}$ : Liver $(\mathbf{F})$ and plasma $(\mathbf{G})$ levels of 9- and 13-HODEs. Data are expressed as means \pm SEM. Each experiment is a representative or the average of $6-10$ mice in each group. ${ }^{\star} P<0.05$. Original magnification: $\times 400(\mathrm{C}) ; \times 200(\mathrm{E})$. HODE, hydroxyoctadecadienoic acid: $\mathrm{SF}$, saturated fat; USF, unsaturated fat.

(the pair-fed mice) received the same amount of isocaloric food (maltodextrin-containing diets) that ethanol-fed animals consumed in the previous day (pair-feeding protocol). At the conclusion of the experiment, the mice were euthanized and portions of liver tissue were snap frozen in liquid nitrogen or were fixed in $10 \%$ neutral-buffered formalin. Blood was collected from the inferior vena cava via venipuncture using heparinized syringes. Plasma was obtained, aliquoted, and stored at $-80^{\circ} \mathrm{C}$ for further analysis. The study protocol was approved by the University of Louisville Institutional Animal Care and Use Committee (Louisville, $\mathrm{KY})$.

\section{Biochemical Analysis and Enzyme-Linked Immunosorbent Assays}

Plasma alanine transaminase (ALT; a marker of liver damage) activities were measured using the Piccolo Xpress chemistry analyzer (Abaxis, Union City, CA). Hepatic lipids were extracted with chloroform and methanol, and triglycerides were measured using Triglycerides Reagent (Thermo Fisher Scientific Inc., Middletown, VA). ${ }^{34}$ Liver thiobarbituric acid reactive substances (TBARSs) were measured in whole-liver homogenate using a commercially available kit (Cayman Chemical, Ann Arbor, MI). Plasma lipopolysaccharide (LPS) levels were measured with the Limulus Amoebocyte Lysate kit (Lonza, Walkersville, MD). Soluble CD14 (R\&D Systems, Minneapolis, MN) and

Table 1 Nutritional Composition of the SF and USF Experimental Diets

\begin{tabular}{lll}
\hline Ingredients & SF diet & USF diet \\
\hline Protein, kcal\% & 17 & 17 \\
Carbohydrate, kcal\% & 43 & 43 \\
Fat, kcal\% & 40 & 40 \\
$\quad$ Saturated FA, \% & 84.1 & 13.2 \\
Monounsaturated FA, \% & 9.3 & 25.0 \\
Polyunsaturated FA, \% & 6.6 & 61.8 \\
\hline
\end{tabular}

FA, fatty acid; SF, saturated fat; USF, unsaturated fat. 
Table 2 Murine Primer Sequences for RT-PCR

\begin{tabular}{|c|c|c|}
\hline Gene & Forward primer & Reverse primer \\
\hline $18 \mathrm{~s}$ & $5^{\prime}$-CTCAACACGGGAAACCTCAC-3' & 5'-CGCTCCACCAACTAAGAACG-3' \\
\hline Tnfa & $5^{\prime}$-GTGATCGGTCCCCAAAGG-3' & 5'-GGTGGTTTGCTACGACGTG-3' \\
\hline Mip2a & $5^{\prime}$-GCGCCCAGACAGAAGTCATA-3' & 5'-TCCAGGTCAGTTAGCCTTGC-3' \\
\hline Mcp1 & $5^{\prime}$-GGCTCAGCCAGATGCAGT-3' & 5'-TGAGCTTGGTGACAAAAACTACAG-3' \\
\hline$I l 1 b$ & $5^{\prime}$-TTCATCTTTGAAGAAGAGCCCAT- $3^{\prime}$ & 5'-TCGGAGCCTGTAGTGCAGTT-3' \\
\hline Nos2 & $5^{\prime}$-GAGACAGGGAAGTCTGAAGCAC-3' & 5'-CCAGCAGTAGTTGCTCCTCTTC-3' \\
\hline
\end{tabular}

lipopolysaccharide binding protein (Hycult Biotech, Plymouth Meeting, PA) were measured by enzyme-linked immunosorbent assays, according to the manufacturers' instructions.

\section{Liver Histological Analysis and Staining}

Mouse liver tissues were collected, fixed in $10 \%$ neutralbuffered formalin solution, and embedded in paraffin. Hematoxylin and eosin staining was performed for liver tissue histological evaluation. Oil-Red-O staining on liver tissue cryostat sections was performed to evaluate hepatic fat accumulation. Apoptotic cells were identified by terminal deoxynucleotidyl transferase dUTP nick-end labeling assay using the ApopTag Peroxidase In Situ Apoptosis Detection kit (Millipore, Billerica, MA). Hepatic neutrophil accumulation was assessed by chloroacetate esterase staining using a commercially available kit (Sigma, St. Louis, MO). Hepatic 4-hydroxy-2-nonenal levels were detected by immunohistochemistry using antibodies from Alpha Diagnostic International (San Antonio, TX).

\section{RNA Isolation and Real-Time RT-PCR Assay}

Total RNA was purified using Trizol reagent (ThermoFisher, Waltham, MA), as described by the manufacturer. To ensure there was no genomic DNA carryover, samples were digested with DNase I (ThermoFisher). cDNA was synthesized using qScript cDNA Supermix (Quanta Biosciences, Beverly, MA). The cDNA equivalent of $10 \mathrm{ng}$ RNA was used in each real-time quantitative PCR (with the exception of $18 \mathrm{~S}$ ribosomal RNA, where $0.1 \mathrm{ng}$ was used). RT-PCR assays were performed with PerfeCTa SYBR Green Fast Mix (Quanta Biosciences) on the Applied Biosystems 7900HT platform (Foster City, CA) using primers listed in Table 2. All data were normalized to the expression of the $18 \mathrm{~S}$ ribosomal RNA gene, and the data were calculated as described previously. ${ }^{35}$

\section{Western Blotting}

Western blotting was performed to evaluate the levels of cytochrome p450 2E1 (CYP2E1) using a commercially available antibody (Abcam, Cambridge, MA). Liver tissue lysates were separated by SDS-PAGE and subsequently transferred to a polyvinylidene difluoride membrane. Blots were visualized using Amersham enhanced chemiluminescence Western blot detection (GE Health Care, Hercules, CA), and quantified using ImageJ software version 1.50i (NIH, Bethesda, MD; http://imagej.nih.gov/ij). Glyceraldehyde-3-phosphate dehydrogenase (Santa Cruz Biotechnology, Dallas, TX) was used as a loading control.

\section{Liver Lipidomic Analysis}

Lipid extraction from liver tissue and quantification of lipid metabolite levels were performed, as previously described, ${ }^{36-39}$ by the Wayne State University Lipidomic Core Facility (Detroit, MI). Briefly, tissue samples were homogenized in phosphate buffer, $\mathrm{pH}$ 7.2. Samples were spiked with internal standards and extracted for PUFA metabolites on C18 extraction columns, as described earlier. ${ }^{36-39}$ Highperformance liquid chromatography was performed on a Prominence XR system (Shimadzu Corp., Kyoto, Japan) using a Luna C18 $(3 \mu \mathrm{m}, 2.1 \times 150 \mathrm{~mm})$ column. Mass spectra for each detected lipid mediator were recorded using the Enhanced Product Ion feature to verify the identity of the detected peak in addition to multiple reaction monitoring transition and retention time match with the standard. The data were collected using Analyst 1.6.2 software (SCIEX, Framingham, MA), and the multiple reaction monitoring transition chromatograms were quantitated by MultiQuant software version 3.0.2 (SCIEX). The internal standard signals in each chromatogram were used for normalization for recovery as well as relative quantitation of each analyte.

\section{Plasma 0xidized Linoleic Acid Metabolites (OXLAMs) Measurement}

Lipid extraction from plasma and quantification of 9- and 13HODE and LA levels were performed as previously described. $^{26,40}$ Briefly, plasma samples with antioxidant solution, internal standards [synthetic $9(\mathrm{~S})$-HODE-d4 or 13(S)HODE-d4], and potassium hydroxide were added to glass test tubes and overlaid with argon. After hydrolysis under argon atmosphere, the released fatty acids were extracted twice into the hexane layer by liquid/liquid extraction. The combined hexane extracts were dried under nitrogen gas and resuspended in $85 \%$ 
Table 3 Body Composition and Metabolic Characteristics of Mice Fed SF or USF Diets in an Experimental Animal Model of Chronic-Binge-Induced Liver Injury

\begin{tabular}{|c|c|c|c|c|}
\hline \multirow[b]{2}{*}{ Parameters } & \multicolumn{2}{|l|}{ SF diet } & \multicolumn{2}{|l|}{ USF diet } \\
\hline & Pair fed & Ethanol & Pair fed & Ethanol \\
\hline \multicolumn{5}{|l|}{ Body/tissue weights } \\
\hline Body weight, g & $24.2 \pm 0.25$ & $21.79 \pm 0.50^{*}$ & $24.3 \pm 0.42$ & $21.2 \pm 0.63^{*}$ \\
\hline Liver weight, $\mathrm{g}$ & $0.82 \pm 0.02$ & $0.97 \pm 0.03^{*}$ & $0.88 \pm 0.03$ & $0.92 \pm 0.02$ \\
\hline Liver/body weight & $0.033 \pm 0.00$ & $0.044 \pm 0.001^{*}$ & $0.036 \pm 0.001$ & $0.043 \pm 0.001^{*}$ \\
\hline eWAT weight, g & $0.46 \pm 0.03$ & $0.15 \pm 0.03^{*}$ & $0.49 \pm 0.05$ & $0.20 \pm 0.04^{\star}$ \\
\hline eWAT/body weight & $0.019 \pm 0.001$ & $0.006 \pm 0.001^{*}$ & $0.02 \pm 0.002$ & $0.009 \pm 0.002^{*}$ \\
\hline \multicolumn{5}{|l|}{ Blood } \\
\hline LPS, EU/mL & $0.16 \pm 0.01$ & $0.14 \pm 0.01$ & $0.21 \pm 0.02$ & $0.15 \pm 0.04$ \\
\hline $\mathrm{LBP}, \mathrm{ng} / \mathrm{mL}$ & $99.61 \pm 30.33$ & $89.39 \pm 23.58$ & $79.10 \pm 19.54$ & $70.02 \pm 23.33$ \\
\hline $\mathrm{sCD} 14, \mathrm{pg} / \mathrm{mL}$ & $817.8 \pm 55.29$ & $1363 \pm 84.51^{*}$ & $710.1 \pm 103.5$ & $1302 \pm 41.57^{*}$ \\
\hline
\end{tabular}

Data are presented as the means \pm SEM. $n=7$ to 10 animals per group.

${ }^{*} P<0.05$ pair-fed versus ethanol-fed mice.

eWAT, epididymal white adipose tissue; LBP, LPS binding protein; LPS, lipopolysaccharide; SCD14, soluble CD14; SF, saturated fat; USF, unsaturated fat.

methanol/water. Reconstituted lipid extracts were analyzed by high-performance liquid chromatography. Oxidized fatty acids were quantified on a triple quadrupole mass spectrometer (API 365; Applied Biosystems, Foster City, CA) with Ionics EP 10p upgrade (Concord, ON, Canada) using the stable isotope dilution method and multiple reaction monitoring with characteristic parent-to-daughter ion transitions.

\section{Cell Culture and Treatments}

RAW264.7 cells (a mouse monocyte/macrophage cell line) were obtained from ATCC (Manassas, VA) and cultured in Dulbecco's modified Eagle's medium supplemented with $10 \%$ fetal bovine serum and $100 \mathrm{U} / \mathrm{mL}$ of penicillin and streptomycin at $37^{\circ} \mathrm{C}$ and $5 \% \mathrm{CO}_{2}$. The 9- and 13-HODEs (supplied in $100 \%$ ethanol) were purchased from Cayman Chemical. Cells were seeded at a density of $2 \times 10^{5}$ cells $/ \mathrm{cm}^{2}$ and incubated with $5 \mu \mathrm{mol} / \mathrm{L}$ 9- or $13-\mathrm{HODE}$ (in the presence of $25 \mathrm{mmol} / \mathrm{L}$ ethanol) or vehicle/control $(25 \mathrm{mmol} / \mathrm{L}$ ethanol) for 24 hours. LPS (from Escherichia coli 0111:B4; Sigma Chemical Co, St. Louis, MO) was then added to a final concentration of $100 \mathrm{ng} / \mathrm{mL}$, and cultures were continued for an additional 3 hours. Cells were washed twice with sterile phosphate-buffered saline and scraped in Trizol (ThermoFisher), and total RNA was purified as described by the manufacturer. The HODE concentration was chosen on the basis of the observation that the circulating HODE levels could reach low micromolar range in humans with ALD. ${ }^{28}$ Five micromolar 9- or 13-HODE is the maximum concentration that did not cause significant cell death in RAW264.7 cells, as determined in our preliminary experiments.

\section{Statistical Analysis}

The data are expressed as the means \pm SEM. For animal studies, statistical significance was determined using either the two-tailed $t$-test or two-way analysis of variance, followed by the Bonferroni multiple comparison test, where appropriate. For cell culture studies, the data were analyzed by one-way analysis of variance. $P<0.05$ was considered statistically significant. Statistical analysis was performed using GraphPad Prism version 5.01 for Windows (GraphPad Software, Inc., La Jolla, CA).

\section{Results}

Liver Injury Caused by a Diet Rich in Linoleic Acid and Chronic-Binge-Ethanol Administration Is Associated with Elevated OXLAM Levels

A mouse model of chronic-binge-ethanol-induced liver injury was used in this study. The animals were fed a Lieber-deCarli control or ethanol-containing diet enriched in SF or USF. We first evaluated the effects of different types of dietary fat in combination with ethanol exposure on body/organ weights (Table 3). Body weights were significantly reduced in response to ethanol administration, regardless of the type of lipids in the diet. When compared to pair-fed mice, those receiving $\mathrm{SF}+$ ethanol had a significant increase in liver weights, whereas USF+ethanol-fed mice had no appreciable differences in liver weights. When expressed in terms of body weight, the liver/body weight ratios were similarly increased in both the SF+ethanol and USF-ethanol groups. Ethanol administration significantly reduced epididymal white adipose tissue as well as epididymal white adipose tissue/body weight ratios regardless of the type of dietary fat. There were no differences in body/organ weights between SF and USF or between SF+ethanol- and USF+ethanol-fed mice.

As a measure of liver injury, we assayed plasma ALT activity and found that it was significantly elevated in the USF+ethanol group when compared to pair-fed controls and to mice fed SF+ethanol (Figure 1B), suggesting a 

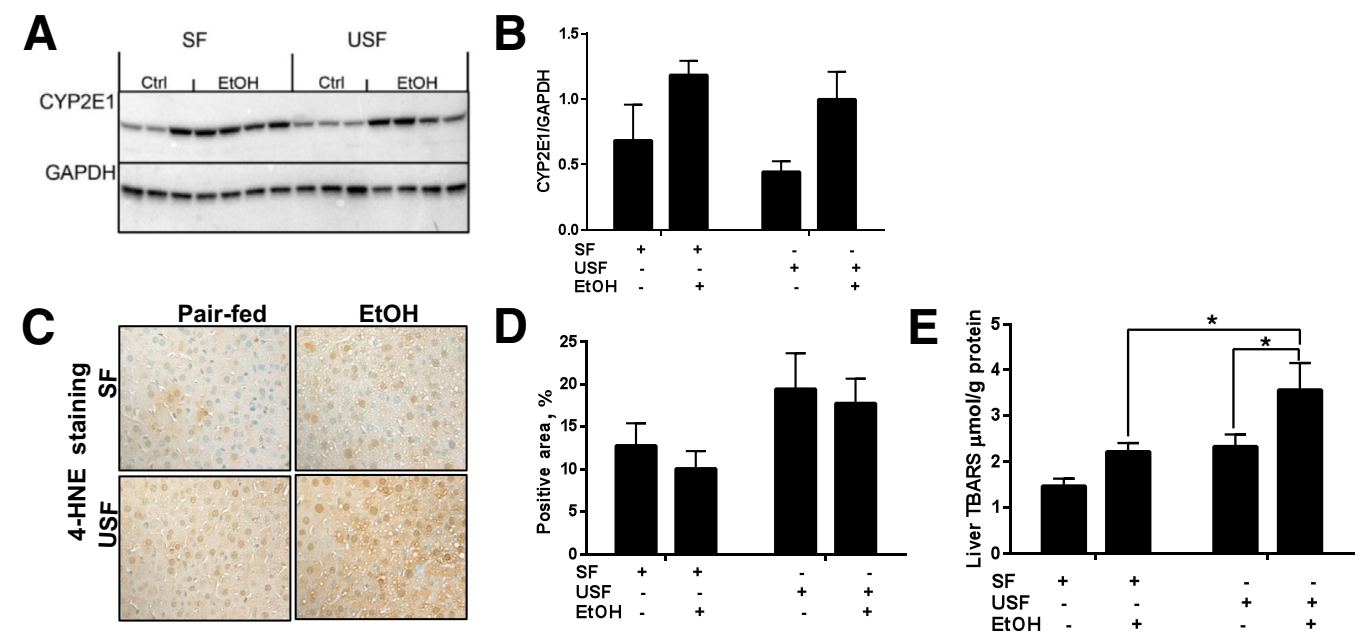

Figure 2 Effect of different types of dietary lipids and chronic ethanol (EtOH) administration on hepatic oxidative stress. A: Cytochrome p450 2E1 (CYP2E1) protein expression analyzed by Western blotting with glyceraldehyde-3-phosphate dehydrogenase (GAPDH) as loading control (Ctrl). B: The intensity of protein bands (from $\mathbf{A}$ ) was quantified by densitometry using the ImageJ software. C and D: Representative images and quantification of hepatic 4-hydroxy2-nonenal staining (4-HNE). Quantification is presented as percentage of 4-HNE-positive area over the entire area of the image slide, and was performed using ImageJ by manually chosen identical thresholds applied to all images being analyzed. E: Hepatic thiobarbituric acid reactive substance (TBARS) levels. Data are expressed as means \pm SEM . Each experiment is a representative of the average of 8-10 mice in each group. ${ }^{*} P<0.05$. Original magnification, $\times 400$ (C). SF, saturated fat; USF, unsaturated fat.

greater degree of hepatocyte injury caused by the combination of a USF diet and chronic-binge ethanol exposure. There were no differences in plasma ALT activity between the SF and USF pair-fed mice groups. Terminal deoxynucleotidyl transferase dUTP nick-end labeling staining revealed a trend toward elevated hepatic apoptosis in response to chronic-binge ethanol exposure predominantly in mice fed the USF diet (data not shown). The gut-liver axis plays an important role in ALD pathogenesis; therefore, we analyzed plasma markers of gut permeability and endotoxemia, including levels of LPS (a Gram-negative bacteria-derived product and classic marker of endotoxemia) and LPS binding protein and soluble CD14 (indirect markers of LPS translocation from the gut lumen into the systemic circulation). There were no differences observed in plasma LPS and LPS binding protein levels between SF and USF control or ethanol-fed animals, whereas soluble CD14 levels were significantly increased in response to ethanol administration regardless of the type of dietary lipids (Table 3). Histological examination of liver sections (Figure 1C), liver triglyceride measurements (Figure 1D), and analysis of hepatic Oil-Red-O staining (Figure 1E) revealed increased fat accumulation in response to ethanol administration regardless of the type of dietary fat. However, the extent of hepatic steatosis was significantly higher in mice fed USF+ethanol. These observations demonstrated that the USF diet exacerbated chronic-binge-ethanol-induced liver steatosis and injury. We and others have previously shown that ethanol-induced liver injury was associated with elevated levels of circulating OXLAMs (specifically, 9- and 13-HODEs), the products of enzymatic and nonenzymatic LA oxidation. ${ }^{29,30}$ In the present study, we observed significant elevations in both liver (Figure 1F) and plasma (Figure 1G) OXLAM levels in USF+ethanol-fed mice, and these mice exhibited more liver injury compared to SF+ethanol-fed animals.

\section{Effect of Saturated or Unsaturated Dietary Fat on Chronic-Binge-Ethanol-Induced Hepatic Oxidative Stress}

Oxidative stress, one of the factors contributing to OXLAM production, is a common feature of ethanol-induced liver damage and plays an important role in ALD pathogenesis. To determine whether the type of dietary fat plays a role in modulating the degree of chronic-binge-ethanol-induced oxidative stress, hepatic levels of CYP2E1, 4-hydroxy-2nonenal, and TBARS were evaluated as surrogate markers of oxidative stress. Consistent with previous reports in different animal models of $\mathrm{ALD},{ }^{6,7}$ hepatic levels of CYP2E1 (the major enzyme for ethanol metabolism) were similarly elevated in SF- and USF-fed mice in response to chronic-binge ethanol administration (Figure 2, A and B). A trend toward elevated intensity of 4-hydroxy-2nonenal-positive staining was observed in the USF and $\mathrm{USF}+$ ethanol compared to the SF and SF+ethanol groups (Figure 2, C and D). Another marker of oxidative stress, hepatic TBARS, was modestly increased by SF+ethanol, but significantly elevated by USF+ethanol compared with control pair-fed animals. There were also significant differences in TBARS levels between SF+ethanol- and USF+ethanol-fed animals (Figure 2E). Of note, the USF diet alone increased hepatic TBARS to levels approximating those seen in the $\mathrm{SF}+$ ethanol group. 
A

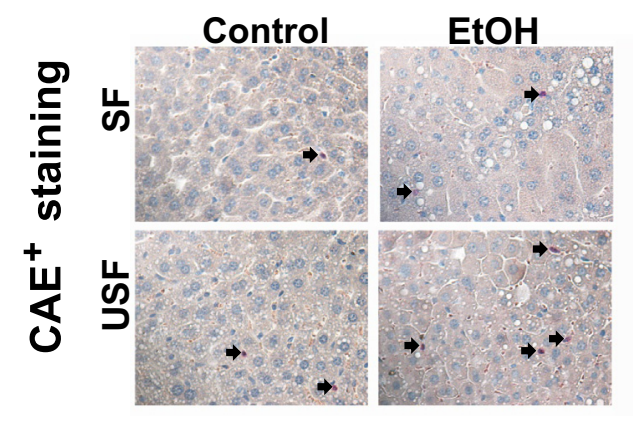

C B

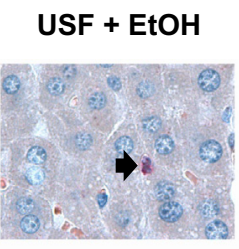

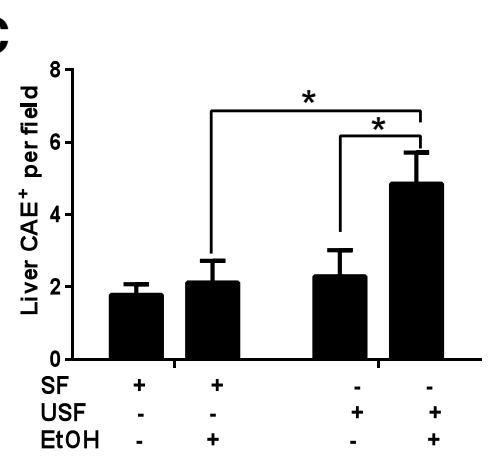

F

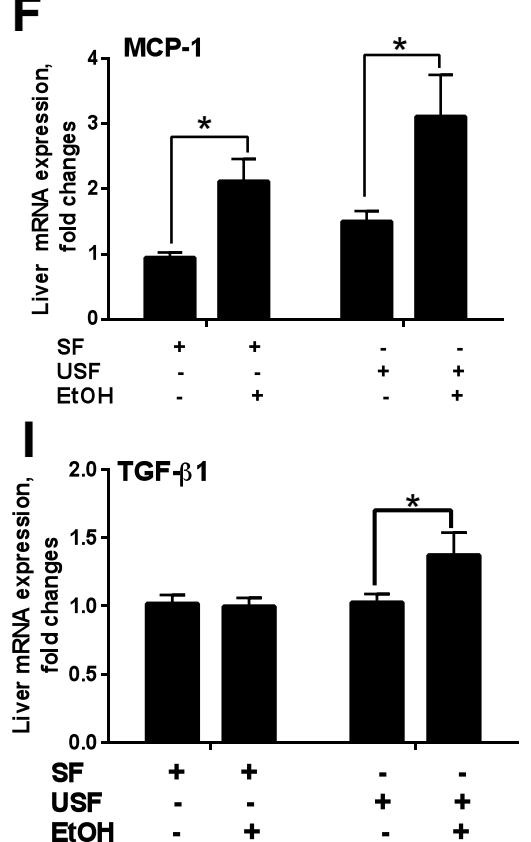

EtOH
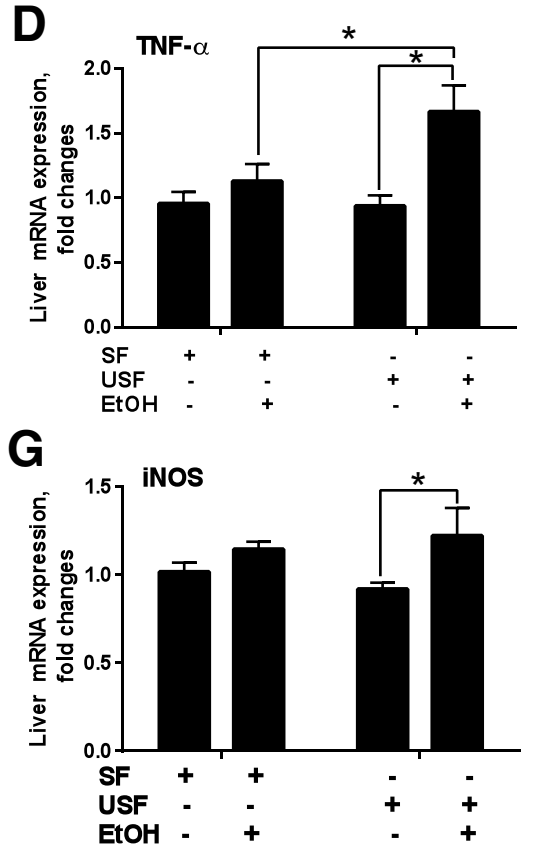

E

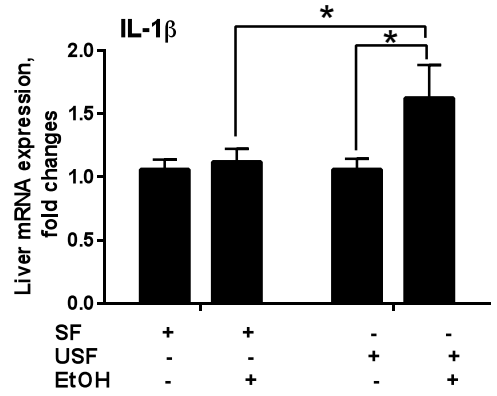

H

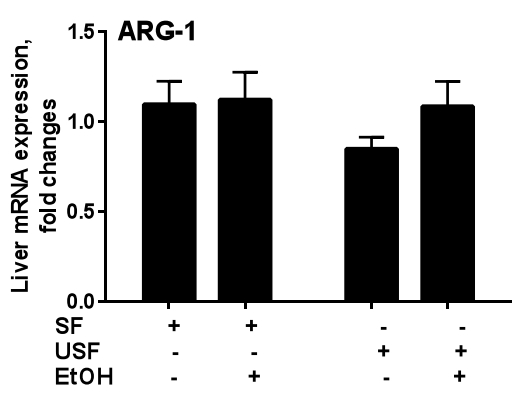

Figure 3 Effect of different types of dietary lipids and chronic-binge-ethanol (EtOH) administration on hepatic inflammation. A and B: Representative images of chloroacetate esterase staining (CAE). Arrows indicate CAE-positive neutrophils. C: Quantification of CAE staining performed by counting CAEpositive neutrophils in a random series of five digital images per animal. D: Tumor necrosis factor- $\alpha$ (TNF- $\alpha$ ). E: IL-1 $\beta$. F: Monocyte chemotactic protein 1 (MCP-1). G: Inducible nitric oxide synthase (iNOS). H: Arginase 1 (ARG-1). I: Transforming growth factor- $\beta 1$ (TGF- $\beta 1$ ). D-I: Hepatic mRNA levels were measured by RT-PCR. Genes were normalized to $18 \mathrm{~S}$ rRNA as an internal control. Results are presented as fold changes relative to the SF pair-fed group. Data are expressed as means \pm SEM. Each experiment is a representative or the average of 8-10 mice per group (D-I). $n=6$ to 8 animals per group (C). ${ }^{*} P<0.05$. Original magnification: $\times 400($ A $) ; \times 1000(B)$. SF, saturated fat; USF, unsaturated fat.

\section{A Linoleic Acid-Enriched Diet Enhances Hepatic Inflammation in Response to Chronic-Binge Ethanol Exposure}

The current chronic-binge ethanol feeding model is known to cause robust hepatic neutrophil infiltration. ${ }^{31}$ In our study, we observed significantly increased numbers of neutrophils in the livers of mice fed USF+ethanol compared to pair-fed controls and to mice fed SF+ethanol (Figure 3, $\mathrm{A}-\mathrm{C})$. There were no differences in liver neutrophil infiltration between mice fed SF and USF diets without alcohol. Expression of key macrophage M1 type (proinflammatory) response genes, including tumor necrosis factor- $\alpha$ (TNF- $\alpha$ ) and IL-1 $\beta$, was significantly increased in response to the USF+ethanol diet compared to pair-fed controls, an effect not observed in SF+ethanol-fed mice (Figure 3, D and E). Of note, hepatic mRNA levels of monocyte chemotactic protein 1 (MCP-1), a chemotactic factor for monocytes/ macrophages, were significantly increased in response to ethanol regardless of the type of dietary fat (Figure 3F). Expression of inducible nitric oxide synthase was elevated in the livers of mice fed the USF+ethanol diet compared to pair-fed animals (Figure 3G). There were no changes in inducible nitric oxide synthase expression in SF+ethanolfed mice compared to controls. No differences were observed in the expression of any liver proinflammatory cytokines between SF and USF in animals fed the control diets. Expression of the macrophage M2 type (anti-inflammatory) response gene, arginase 1 , was not altered by the ethanol administration or type of dietary fat, whereas 

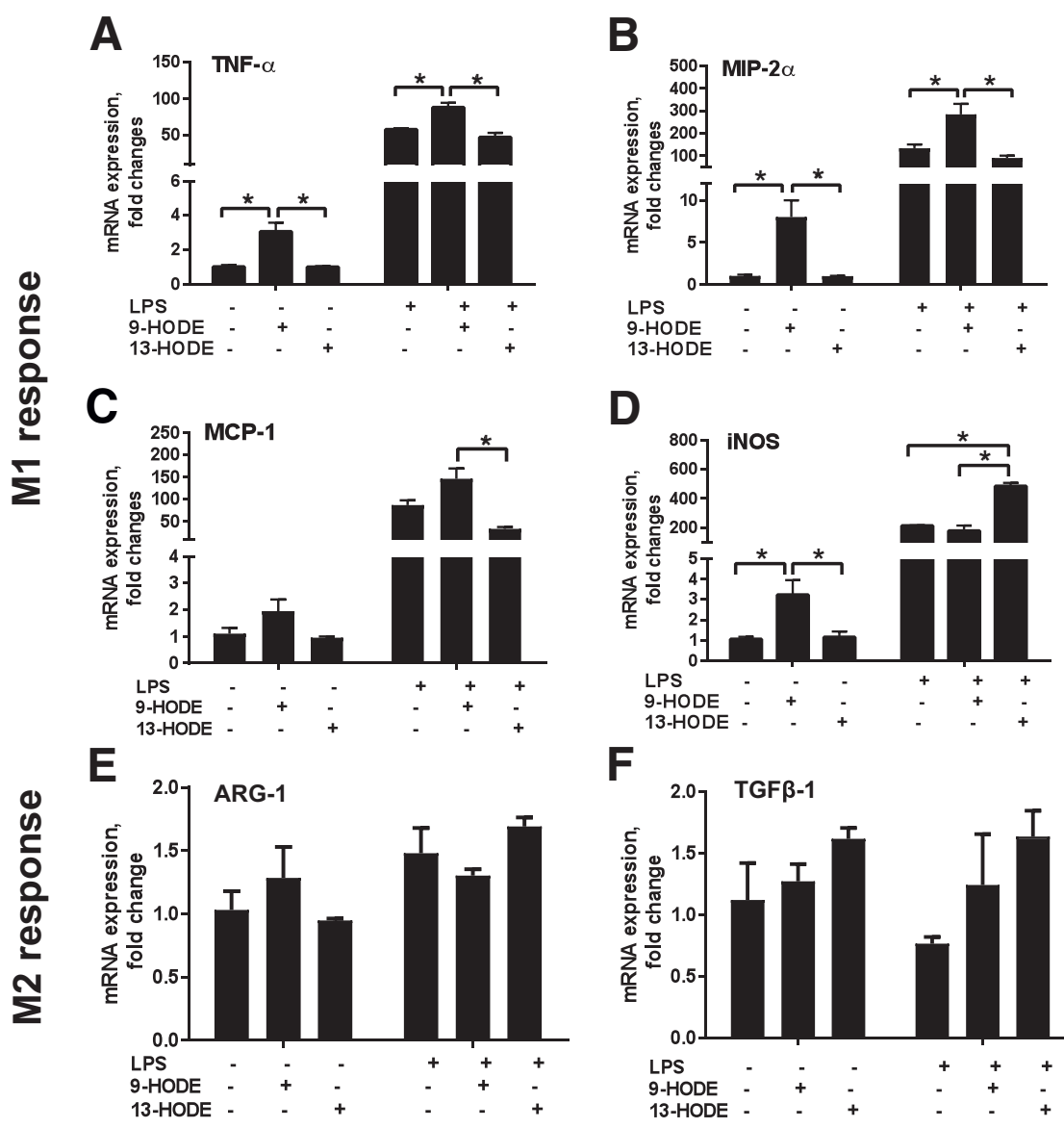

Figure 4 The 9- and 13-HODE-induced cyto-

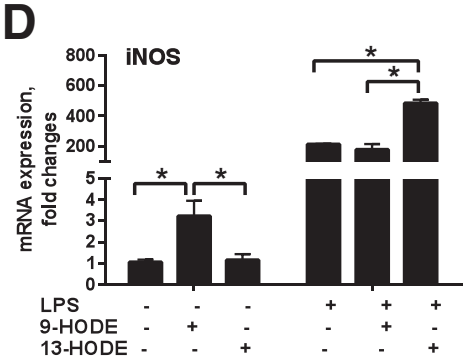
kine expression in RAW264.7 macrophages. A-D: RT-PCR analysis of the expression of M1 macrophage markers: A: Tumor necrosis factor- $\alpha$ (TNF- $\alpha$ ). B: Macrophage inflammatory protein-2 $\alpha$ (MIP-2 $\alpha$ ). C: Monocyte chemoattractant protein-1 (MCP-1). D: Inducible nitric oxide synthase (iNOS). E and F: M2 macrophage markers: arginase-1 (ARG-1) (E) and transforming growth factor- $\beta$ (TGF- $\beta 1$ ) (F). mRNA levels were measured by RT-PCR. Genes were normalized to $18 \mathrm{~S}$ rRNA as an internal control. Results are presented as fold change relative to $\mathbf{F}$

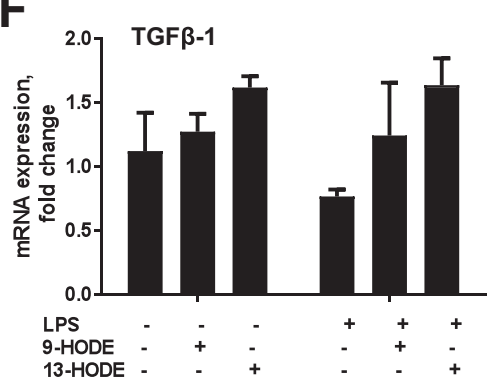
vehicle/control $(25 \mathrm{mmol} / \mathrm{L}$ ethanol). Data are expressed as means \pm SEM. $n=3(\mathbf{A}-\mathbf{F})$. ${ }^{*} P<0.05$. HODE, hydroxyoctadecadienoic acid.

transforming growth factor- $\beta 1$ was up-regulated in USF+ethanol-fed mice and was unchanged in SF+ethanolfed mice (Figure 3, H and I). Taken together, a USF compared to SF diet enhanced ethanol-mediated hepatic neutrophil infiltration and increased the macrophage M1 proinflammatory response (with the exception of MCP-1 mRNA, which was up-regulated in both $\mathrm{SF}+$ ethanol and USF+ethanol groups).

\section{Oxidized Metabolites of Linoleic Acid Induce Proinflammatory Response in Macrophages}

To directly determine the effect of OXLAMs on cytokine expression, we assayed their effect on RAW264.7 cells, a mouse monocyte/macrophage cell line. RAW264.7 cells were treated overnight with $5 \mu \mathrm{mol} / \mathrm{L}$ 9- or 13-HODE or vehicle $(25 \mathrm{mmol} / \mathrm{L}$ ethanol) and then with or without 100 $\mathrm{ng} / \mathrm{mL}$ LPS for 3 hours. The expression of several cytokines was then determined by RT-PCR. Stimulation of RAW264.7 cells by 9-HODE alone, but not 13-HODE alone, led to a significant increase in TNF- $\alpha$ expression (Figure 4A). A similar pattern was observed when the expression of macrophage inflammatory protein- $2 \alpha$ and MCP-1 was assayed (Figure 4, B and C), where 9-HODE alone and in combination with LPS enhanced their expression, but 13-HODE alone did not; rather, it slightly attenuated LPS induction of these two cytokines. In contrast, 13-HODE, but not 9-HODE, potentiated LPS induction of inducible nitric oxide synthase expression (Figure 4D). These results demonstrate that 9- and 13-HODEs have different, and sometimes opposing, roles in regulating cytokine gene expression in RAW264.7 cells, with 9-HODE promoting a proinflammatory response (M1 response) to a greater extent than 13-HODE. To determine the effect on the resolution phase of the inflammatory response (M2 response), the expression of arginase 1 and transforming growth factor- $\beta 1$ was determined. There were no statistically significant effects of either 9- or 13-HODE on the expression of arginase 1 or transforming growth factor- $\beta 1$ mRNA levels (Figure 4, E and F).

\section{Loss of Alox15 Expression Modestly Attenuates} Chronic-Binge-Ethanol-Induced Liver Injury with No Effect on Hepatic Steatosis

12/15-LO is the main enzyme involved in LA oxidation and OXLAM production and may represent a therapeutic target in ALD. Therefore, we questioned whether deficiency of 
Table 4 Body Composition of WT and Alox $15^{-/-}$Mice in an Experimental Animal Model of Chronic-Binge-Induced Liver Injury

\begin{tabular}{|c|c|c|c|c|}
\hline \multirow[b]{2}{*}{ Parameters } & \multicolumn{2}{|l|}{ WT } & \multicolumn{2}{|l|}{ Alox $15^{-/-}$} \\
\hline & Pair fed & Ethanol & Pair fed & Ethanol \\
\hline \multicolumn{5}{|l|}{ Body/tissue weights } \\
\hline Liver weight, $\mathrm{g}$ & $0.77 \pm 0.04$ & $0.94 \pm 0.02 *$ & $0.72 \pm 0.04$ & $0.97 \pm 0.01^{*}$ \\
\hline Liver/body weight & $0.032 \pm 0.0008$ & $0.044 \pm 0.001^{*}$ & $0.035 \pm 0.001$ & $0.047 \pm 0.001^{*}$ \\
\hline eWAT weight, $g$ & $0.37 \pm 0.03$ & $0.23 \pm 0.04^{*}$ & $0.27 \pm 0.02$ & $0.15 \pm 0.02$ \\
\hline
\end{tabular}

Data are presented as the means + SEM. $n=7$ to 10 animals per group.

${ }^{*} P<0.05$ pair-fed versus ethanol-fed mice.

eWAT, epididymal white adipose tissue; WT, wild-type.

Alox 15, the gene encoding $12 / 15-\mathrm{LO}$, would reduce OXLAM levels and attenuate liver damage caused by the combination of ethanol and an LA-rich diet. We used a chronic-binge-ethanol-induced model of ALD, where Alox $15^{-1-}$ and WT mice were fed USF (LA-enriched) control- or ethanol-containing diets. Body composition measurements revealed that the body weights of Alox $15^{-1-}$ mice were slightly lower than WT mice, but neither group had any significant weight loss because of ethanol (Table 4). However, the liver weight and liver/body weight ratio was significantly increased in both Alox $15^{-1-}$ and WT mice in response to ethanol feeding. There was a reduction in the amount of epididymal white adipose tissue in both groups, although epididymal white adipose tissue/body weight ratios were similar in the pair-fed and ethanol groups. Control diet-fed Alox $15^{-/-}$mice had modestly, but not significantly, lower levels of liver OXLAMs, including 9and 13-HODEs, compared to WT animals (Figure 5, A and B). However, OXLAM levels were similarly elevated in livers in both WT and Alox $15^{-/-}$mice in response to chronic-binge ethanol exposure. In addition to OXLAMs, we measured hydroxyeicosatetraenoic acids (HETEs), which are the 12/15-LO oxidation products of arachidonic acid. There were no noticeable differences in the levels of 15-HETE between Alox $15^{-1-}$ and WT mice, whereas 12-HETE levels trended lower in Alox $15^{-1-}$ compared to WT mice in both control- and ethanol-fed mice (Figure 5, C and D). Notably, the degree of hepatic steatosis was similar in WT and Alox $15^{-1-}$ mice fed ethanol-containing diets (Figure 5, E and F), whereas chronic-binge-ethanol challenge in WT resulted in greater liver injury (compared to controls) than in Alox15 $1-$ mice (Figure 5G). The
A

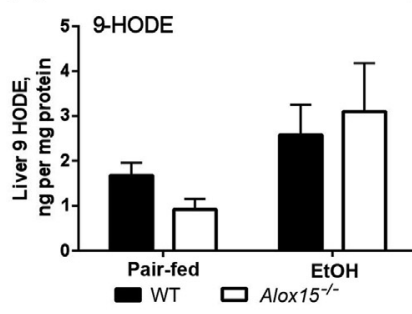

B

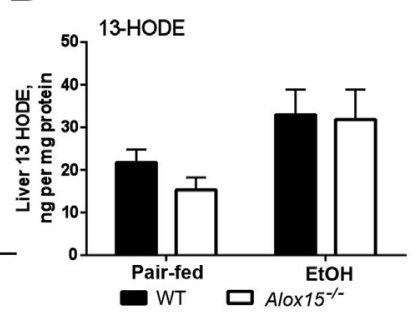

C

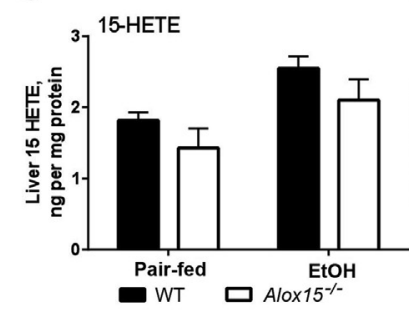

D

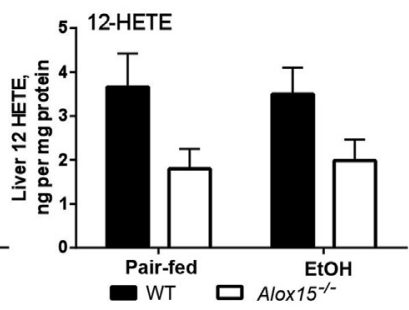

G

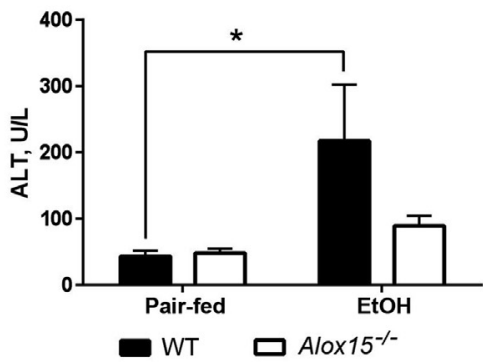

Figure 5 Genetic deletion of Alox15 modestly attenuates chronic-binge-ethanol (EtOH)-induced liver injury with no effect of hepatic steatosis. A and B: Liver levels of 9- and 13-HODEs. C and D: Liver 15- and 12-HETE levels. E: Representative images of hepatic hematoxylin and eosin (H\&E) staining. F: Biochemical assessment of liver triglycerides (TGs). G: Serum ALT levels (data are from two independent experiments). Data are expressed as means \pm SEM. Each experiment is a representative or the average of $5-8$ mice per group. ${ }^{*} P<0.05$. Original magnification, $\times 400$ (E). WT, wild-type. HETE, hydroxyeicosatetraenoic acid; HODE, hydroxyoctadecadienoic acid. 

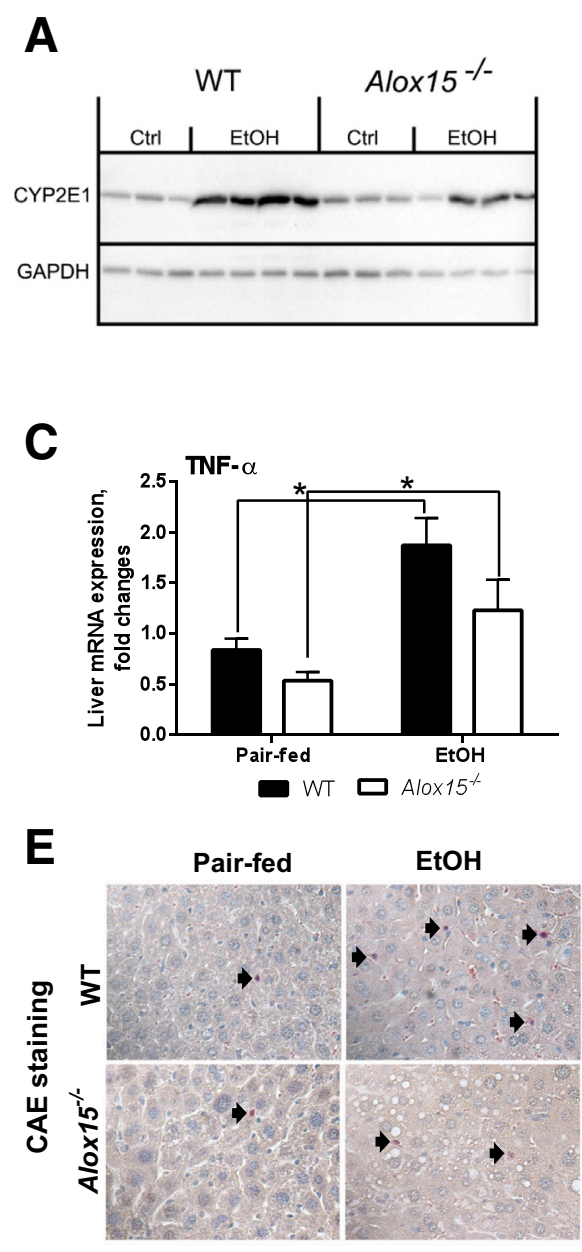
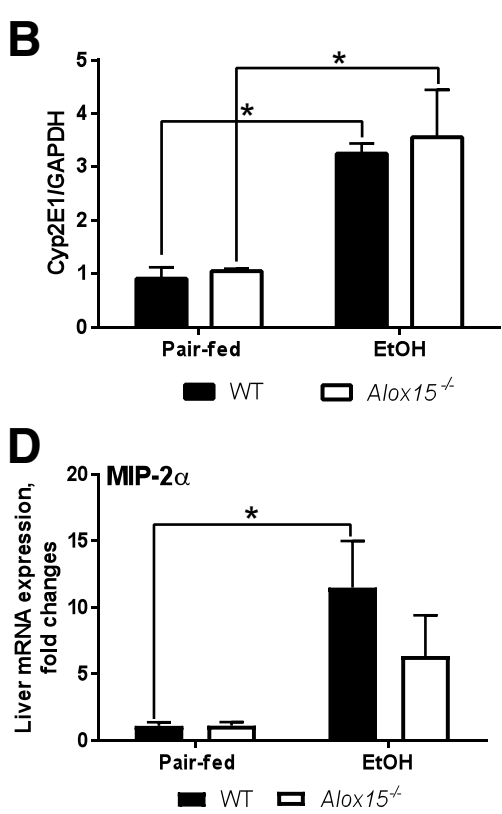

$\mathbf{F}$

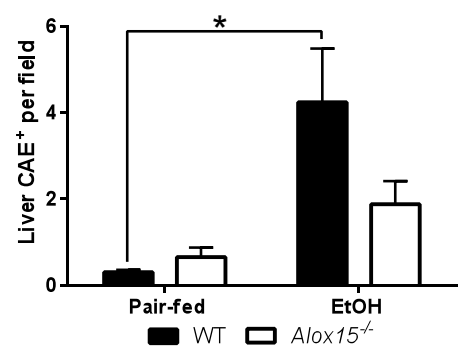

Figure 6 Effect of Alox15 deficiency on cytochrome p450 2E1 (CYP2E1) expression and markers of liver inflammation. A: CYP2E1 protein expression analyzed by Western blotting with glyceraldehyde-3-phosphate dehydrogenase (GAPDH) as loading control (Ctrl). B: The intensity of protein bands (from $\mathbf{A}$ ) was quantified by densitometry using the ImageJ software. C: Tumor necrosis factor- $\alpha$ (TNF- $\alpha$ ) mRNA. D: Macrophage inflammatory protein 2- $\alpha$ (MIP-2 $\alpha$ ) mRNA. C and D: Hepatic mRNA levels were measured by RT-PCR. Genes were normalized to $18 \mathrm{~S}$ rRNA as an internal control. E: Representative images of chloroacetate esterase staining (CAE; arrows indicate CAEpositive neutrophils). F: Quantification of CAE staining performed by counting CAE-positive neutrophils in a random series of five digital images per animal. Results are presented as fold changes relative to the WT pair-fed group. Data are expressed as means \pm SEM. Each experiment is a representative or the average of 5-8 mice per group. ${ }^{*} P<0.05$. Original magnification, $\times 400$ (E). EtOH, ethanol; WT, wild-type. expression of CYP2E1 was similarly increased by ethanol in both WT and Alox15 $5^{-1-}$ mice (Figure 6, A and B). Furthermore, in comparison to pair-fed control groups, the expression of TNF- $\alpha$ and macrophage inflammatory protein- $2 \alpha$ (proinflammatory cytokines) was elevated in the livers of both WT and Alox15 $5^{-/-}$ethanol-fed mice (Figure 6, C and D). Analysis of chloroacetate esterase staining revealed lower levels of hepatic neutrophil infiltration in Alox $15^{-1-}$ compared to WT animals in response to ethanol exposure (Figure 6, E and F). Collectively, these data demonstrate that disruption of the 12/15-LO pathway was not sufficient to decrease ethanol-induced OXLAM levels; nevertheless, Alox15 gene knockout attenuated liver injury caused by LA-enriched diet and chronic-bingeethanol exposure.

\section{Discussion}

In the present study, we report that the combination of ethanol and a diet rich in LA, an $\omega-6$ PUFA, exacerbated chronic-binge-ethanol-induced liver damage in mice. This is in agreement with previously published studies in various murine models of chronic-ethanol-induced ALD, ${ }^{6,7}$ confirming the harmful effects of dietary LA in experimental ALD regardless of the nature of ethanol administration. The results from this study suggest that an increase in OXLAMs (specifically 9-HODE), which can potently induce a proinflammatory response in macrophages, is likely one of the mechanisms triggering the progression from alcoholinduced steatosis to alcoholic steatohepatitis.

Liver steatosis is an early response to ethanol exposure. In line with previous reports, ${ }^{6,7}$ the degree of chronic-bingeethanol-induced hepatic steatosis in our study was greater in mice fed a USF (corn oil/LA-enriched) compared to animals fed an SF (medium-chain triglyceride oil-enriched) diet. One of the critical points in ALD pathogenesis is progression from simple steatosis to alcoholic steatohepatitis, which is characterized by the combination of hepatic fat accumulation and inflammation. An increase in neutrophil infiltration and proinflammatory cytokine production is a hallmark of ethanol-induced liver inflammation. Neutrophils (polymorphonuclear leukocytes, a major innate immune cell subset) play a central role in the host defense against infection- and sterile-based types of inflammation. After alcohol consumption, neutrophils might be recruited to the 
liver by chemoattractant cytokines and through their recognition of damage-associated molecular patterns (eg, high mobility group box-1) that are released from the damaged hepatocytes. ${ }^{41,42}$ The enhanced accumulation of neutrophils in hepatic tissue may lead to elevated production of proinflammatory mediators, reactive oxygen species, and production/release of proteases and hypochlorous acid, ${ }^{43}$ thus exacerbating liver injury. ${ }^{44}$ Our observation of increased neutrophil numbers in the livers of ethanol-fed mice is consistent with previous reports using this animal model of $\mathrm{ALD},{ }^{45}$ and suggests that elevated hepatic neutrophil infiltration in response to ethanol and USF compared to SF diet might be one of the contributing factors to more severe liver injury observed in these animals. In our study, USF+ethanol compared to SF+ethanol administration resulted in enhanced hepatic M1 type macrophage proinflammatory responses with significant elevation of TNF- $\alpha$ and IL-1 $\beta$ gene expression. Dysfunction of intestinal tight junction integrity, elevated endotoxemia, and associated Toll-like receptor-4-mediated increase in production of proinflammatory cytokines in liver macrophages have been implicated in the harmful effects of dietary USF in comparison to the protective effects of dietary SF in experimental animal models of ALD. ${ }^{7,14,46,47}$ Previous studies have reported either elevated or unchanged serum endotoxin levels in this particular (chronic-binge ethanol exposure) experimental model of ALD in mice. ${ }^{30,48,49}$ In the present study, we observed no differences in LPS levels between SF and USF control- or ethanol-fed animals, suggesting that other factors (eg, diet-derived mediators) might contribute to the liver injury caused by USF and chronicbinge ethanol exposure. In this regard, elevated levels of endogenous hepatic and circulating OXLAMs associated with USF and ethanol-induced liver inflammation and injury are one of the most important findings of the current study. Moreover, the increase in 9- and 13-HODE levels observed in the current study, in the chronic-binge ethanol model of ALD, as well as in chronic ethanol-induced ALD in mice (I.A.K., unpublished data), likely represents one of the common diet-dependent pathways/mechanisms contributing to ethanol-induced liver damage. The 9- and 13-HODEs can be formed enzymatically from LA, primarily via the actions of cellular lipoxygenases (eg, 12/15-LO), or nonenzymatically via free radical-mediated oxidation in response to oxidative stress. Elevated levels of hepatic CYP2E1, a marker of oxidative stress, were found in our study (in response to chronic-binge ethanol exposure) as well as in previous studies (in chronic ethanol feeding models ${ }^{6,7}$ ), regardless of the type of dietary fat. The level of TBARS was elevated to a greater extent in USF+ethanol- compared to SF+ethanol-fed animals. This could be because of a high content of LA in a USF diet, which is prone to oxidative degradation, leading to production of a variety of oxidative metabolites. Therefore, oxidative stress and availability of the substrate (LA-enriched diet versus medium-chain triglyceride-enriched diet) are, most likely, contributing factors to the elevated levels of OXLAMs observed in mice fed USF+ethanol compared to SF+ethanol-fed animals. Elevated plasma 9- and 13-HODE levels have been found in rodents in parallel with alcohol-induced hepatic steatosis, oxidative stress, and hepatocyte damage, ${ }^{29,30}$ and in patients with alcoholic cirrhosis. ${ }^{28}$ In the study by RaszejaWyszomirska et $\mathrm{al}^{28}$ the authors demonstrated that the concentrations of HODEs and HETEs were significantly different between healthy individuals, nonalcoholic fatty liver disease patients, and ALD patients. Specifically, patients with ALD had 46 times higher HODE levels than healthy subjects, and more than four times greater HODE levels than nonalcoholic fatty liver disease patients. Furthermore, HODE levels were higher in men with ALD compared to women with ALD. In addition, the expression of ALOX15 and ALOX15B was increased in patients with ALD compared to healthy controls.

The central hypothesis of the current study was that a diet with a high content of LA exacerbates ethanol-induced injury, in part via increased OXLAM production and OXLAM-mediated induction of hepatic proinflammatory responses. By using RAW264.7 cells, we directly tested the effect of each HODE on the production of inflammatory cytokines in a monocyte/macrophage cell type. In general, we found that 9-HODE increased proinflammatory cytokines, either alone or in combination with LPS. We also found that 13-HODE was largely ineffective, and even opposed to the activity of 9-HODE with respect to LPSinduced cytokine expression (Figure 4). There was no effect of either 9- or 13-HODE on the expression of M2 macrophage markers, suggesting that 9-HODE was primarily proinflammatory and that $13-\mathrm{HODE}$ was mainly neutral or had some anti-inflammatory activity. These data are consistent with previous reports of differential activities of 9- and 13-HODE. In studies using human keratinocytes, Hattori et $\mathrm{al}^{22}$ demonstrated that 9-HODE, acting through G-protein coupled receptor (GPR)132, stimulated the expression of IL-6. However, they found no effect by 13 HODE. There are three known receptors for HODES: GPR132, transient receptor potential vanilloid 1 (TRPV1), and peroxisome proliferator-activated receptor $\gamma$ (PPAR $\gamma$ ). GPR132 binds to 9-HODE but binds only weakly to 13HODE. ${ }^{18}$ TRPV1 and PPAR $\gamma$ can bind to both 9- and 13HODE. ${ }^{25,50}$ RAW264.7 cells do not express TRPV $1^{51}$ and express only low levels of PPAR $\gamma .{ }^{52}$ Therefore, the primary response to HODEs in RAW264.7 cells is likely mediated by GPR 132 and explains the relative inactivity of 13-HODE in these cells. Although GPR132 is the primary HODE receptor expressed in macrophages, ${ }^{53}$ the expression of TRPV1 and PPAR $\gamma$ is much more widespread. PPAR $\gamma$ is found in adipose tissue, the small intestine, muscle, brain, and liver, ${ }^{54,55}$ and TRPV1 has been found to be expressed in the liver ${ }^{56}$ and brain. ${ }^{57}$ Therefore, HODEs may affect multiple organ systems, including the liver, by acting through other receptors. Indeed, we have previously shown that $\operatorname{Trpv1} 1^{-1-}$ mice have much improved indexes of liver 
injury and inflammation, such as decreased plasma ALT and decreased expression of several markers of inflammation (eg, TNF- $\alpha$, IL-1 $\beta$, IL- $1 \alpha$, IL-6, MCP-1, and macrophage inflammatory protein- $2 \alpha$ ) after ethanol feeding. ${ }^{30}$

$12 / 15$-LO is the major enzymatic pathway of OXLAM production, and 12/15-LO deficiency protects against highfat diet-induced insulin resistance, adipose tissue inflammation, and nonalcoholic fatty liver disease. ${ }^{58-61}$ Thus, 12/ 15-LO knockout mice were protected from high-fat die$\mathrm{t}$-induced liver steatosis, liver inflammation, and lymphocyte infiltration in the liver. ${ }^{61}$ Disruption of Alox15 in hyperlipidemic $A p o E^{-/-}$mice resulted in reduced serum ALT levels, decreased hepatic steatosis, inflammation with significant reductions in the expression of TNF- $\alpha$, IL-18, and MCP-1, and macrophage infiltration, all of which were associated with lower hepatic 12-HETE levels. ${ }^{60}$ In addition, the absence of Alox15 reduced hepatocyte apoptosis, as revealed by reduced caspase- 3 levels. ${ }^{60}$ In our study, Alox 15 deficiency in mice resulted in the attenuation of ethanol-induced liver injury; however, there was no effect on hepatic steatosis. This might be because of the decreased levels of ALOX15-generated metabolites, some of which could be hepatotoxic. Notably, the absence of Alox15 in mice did not appreciably alter chronic-binge-ethanolinduced OXLAM levels. This observation suggests that nonenzymatic LA oxidation via free radical-mediated oxidation in response to oxidative stress, rather than through the 12/15-LO pathway of LA oxidation, is likely the main mechanism contributing to ethanol-mediated increase in OXLAM production. Another potential source of OXLAM production is that mediated by the cytochrome P450 system $^{62,63}$; however, the significance of this pathway in ALD at this point is unclear. Although the absence of Alox15 conferred partial protection to the liver, that protection cannot be attributed to lower OXLAM levels, as liver 9- and 13-HODEs were similarly elevated in response to ethanol in WT and Alox $15^{-1-}$ mice. This suggests that other 12/15LO-derived metabolites (eg, HETEs, the products of arachidonic acid oxidation) may play a role. Among several HETEs, 12-HETE (a major product of 12/15-LO in rodents) was reduced in the liver tissue from ethanol-fed Alox $15^{-1-}$ compared to WT mice. 12-HETE is a known proinflammatory lipid mediator through the induction of TNF- $\alpha$, MCP-1, and IL-6 expression in macrophages. ${ }^{64,65} \mathrm{An}$ increase in 12-HETE was observed in patients with ALD, ${ }^{28}$ and was associated with liver inflammation and injury in hyperlipidemia-prone $A p o E^{-1-}$ mice; genetic disruption of Alox 15 protected these mice against liver injury. ${ }^{60}$ In addition, the lower levels of other proinflammatory lipid mediators from arachidonic acid [eg, leukotriene $\mathrm{B}_{4}$ (previously implicated in neutrophil recruitment $\left.\left.{ }^{66-68}\right)\right]$ in Alox $15^{-1-}$ compared to WT mice (I.A.K., unpublished data) might confer a decrease of neutrophil infiltration observed in ethanol-fed Alox $15^{-1-}$ compared to WT animals. Notably, the 12/15-LO pathway plays an important role in both inflammation and production of factors that promote resolution of inflammation (eg, lipoxin $\mathrm{A}_{4}$ ). ${ }^{69,70}$ Therefore, further studies examining the role of various lipid mediators involved in the development, progression, or resolution of ethanol-mediated inflammation are warranted.

In summary, the results of the current study support the concept that dietary LA, a $\omega$-6-PUFA, exacerbates ethanolinduced liver injury and provides evidence that the increase in OXLAM production and promotion of an OXLAMmediated proinflammatory response might be one of the underlying mechanisms. Strategies to decrease LA consumption through dietary modifications may be an effective approach to reduce ethanol-induced OXLAMs and to attenuate ALD.

\section{Acknowledgments}

We thank Jingwen Zhang and Ying Song for assistance with tissue staining, and Marion McClain for proofreading the manuscript.

I.A.K., C.E.R., A.E.F., and C.J.M. designed the study and interpreted the data; A.E.F. and S.S. performed OXLAM analyses; B.G. provided critical discussion; H.L. and M.E.M. performed animal studies and acquired data; D.R.W. acquired and analyzed data; I.A.K. and D.R.W. wrote the manuscript.

\section{References}

1. McClain CM, Carithers RL: Alcoholic liver disease. Edited by Feldman M, Friedman L, Brandt L. In Sleisenger and Fordtran's Gastrointestinal and Liver Disease Pathophysiology/Diagnosis/Management. ed 8. Philadelphia, PA: Saunders Elsevier, 2006. pp. 1771-1792

2. D'Amico G, Garcia-Tsao G, Pagliaro L: Natural history and prognostic indicators of survival in cirrhosis: a systematic review of 118 studies. J Hepatol 2006, 44:217-231

3. Wakim-Fleming J, Mullen KD: Long-term management of alcoholic liver disease. Clin Liver Dis 2005, 9:135-149

4. Nanji AA, French SW: Dietary factors and alcoholic cirrhosis. Alcohol Clin Exp Res 1986, 10:271-273

5. Nanji AA, Yang EK, Fogt F, Sadrzadeh SM, Dannenberg AJ: Medium chain triglycerides and vitamin E reduce the severity of established experimental alcoholic liver disease. J Pharmacol Exp Ther 1996, 277:1694-1700

6. Ronis MJ, Korourian S, Zipperman M, Hakkak R, Badger TM: Dietary saturated fat reduces alcoholic hepatotoxicity in rats by altering fatty acid metabolism and membrane composition. J Nutr 2004, 134: 904-912

7. Kirpich IA, Feng W, Wang Y, Liu Y, Barker DF, Barve SS, McClain CJ: The type of dietary fat modulates intestinal tight junction integrity, gut permeability, and hepatic toll-like receptor expression in a mouse model of alcoholic liver disease. Alcohol Clin Exp Res 2012, 36:835-846

8. Chen P, Torralba M, Tan J, Embree M, Zengler K, Starkel P, van Pijkeren JP, DePew J, Loomba R, Ho SB, Bajaj JS, Mutlu EA, Keshavarzian A, Tsukamoto H, Nelson KE, Fouts DE, Schnabl B: Supplementation of saturated long-chain fatty acids maintains intestinal eubiosis and reduces ethanol-induced liver injury in mice. Gastroenterology 2015, 148:203-214.e16 
9. Zhong W, Li Q, Xie G, Sun X, Tan X, Sun X, Jia W, Zhou Z: Dietary fat sources differentially modulate intestinal barrier and hepatic inflammation in alcohol-induced liver injury in rats. Am J Physiol Gastrointest Liver Physiol 2013, 305:G919-G932

10. Nanji AA, French SW: Dietary linoleic acid is required for development of experimentally induced alcoholic liver injury. Life Sci 1989, 44:223-227

11. Li Q, Zhong W, Qiu Y, Kang X, Sun X, Tan X, Zhao Y, Sun X, Jia W, Zhou Z: Preservation of hepatocyte nuclear factor-4alpha contributes to the beneficial effect of dietary medium chain triglyceride on alcohol-induced hepatic lipid dyshomeostasis in rats. Alcohol Clin Exp Res 2013, 37:587-598

12. You M, Fischer M, Deeg MA, Crabb DW: Ethanol induces fatty acid synthesis pathways by activation of sterol regulatory element-binding protein (SREBP). J Biol Chem 2002, 277:29342-29347

13. You M, Rogers CQ: Adiponectin: a key adipokine in alcoholic fatty liver. Exp Biol Med (Maywood) 2009, 234:850-859

14. Nanji AA: Role of different dietary fatty acids in the pathogenesis of experimental alcoholic liver disease. Alcohol 2004, 34:21-25

15. Nanji AA, Griniuviene B, Sadrzadeh SM, Levitsky S, McCully JD: Effect of type of dietary fat and ethanol on antioxidant enzyme mRNA induction in rat liver. J Lipid Res 1995, 36:736-744

16. Kirpich IA, Petrosino J, Ajami N, Feng W, Wang Y, Liu Y, Beier JI, Barve SS, Yin X, Wei X, Zhang X, McClain CJ: Saturated and unsaturated dietary fats differentially modulate ethanol-induced changes in gut microbiome and metabolome in a mouse model of alcoholic liver disease. Am J Pathol 2016, 186:765-776

17. Mutlu E, Keshavarzian A, Engen P, Forsyth CB, Sikaroodi M, Gillevet P: Intestinal dysbiosis: a possible mechanism of alcohol-induced endotoxemia and alcoholic steatohepatitis in rats. Alcohol Clin Exp Res 2009, 33 : 1836-1846

18. Obinata $\mathrm{H}$, Hattori $\mathrm{T}$, Nakane $\mathrm{S}$, Tatei $\mathrm{K}$, Izumi $\mathrm{T}$ : Identification of 9 hydroxyoctadecadienoic acid and other oxidized free fatty acids as ligands of the G protein-coupled receptor G2A. J Biol Chem 2005, 280:40676-40683

19. Blasbalg TL, Hibbeln JR, Ramsden CE, Majchrzak SF, Rawlings RR: Changes in consumption of omega- 3 and omega- 6 fatty acids in the United States during the 20th century. Am J Clin Nutr 2011, 93: 950-962

20. Alvheim AR, Malde MK, Osei-Hyiaman D, Lin YH, Pawlosky RJ, Madsen L, Kristiansen K, Froyland L, Hibbeln JR: Dietary linoleic acid elevates endogenous 2-AG and anandamide and induces obesity. Obesity (Silver Spring) 2012, 20:1984-1994

21. Hatley ME, Srinivasan S, Reilly KB, Bolick DT, Hedrick CC: Increased production of 12/15 lipoxygenase eicosanoids accelerates monocyte/endothelial interactions in diabetic $\mathrm{db} / \mathrm{db}$ mice. J Biol Chem 2003, 278:25369-25375

22. Hattori T, Obinata H, Ogawa A, Kishi M, Tatei K, Ishikawa O, Izumi T: G2A plays proinflammatory roles in human keratinocytes under oxidative stress as a receptor for 9-hydroxyoctadecadienoic acid. J Invest Dermatol 2008, 128:1123-1133

23. Mabalirajan U, Rehman R, Ahmad T, Kumar S, Singh S, Leishangthem GD, Aich J, Kumar M, Khanna K, Singh VP, Dinda AK, Biswal S, Agrawal A, Ghosh B: Linoleic acid metabolite drives severe asthma by causing airway epithelial injury. Sci Rep $2013,3: 1349$

24. Vangaveti VN, Jansen H, Kennedy RL, Malabu UH: Hydroxyoctadecadienoic acids: oxidised derivatives of linoleic acid and their role in inflammation associated with metabolic syndrome and cancer. Eur J Pharmacol 2016, 785:70-76

25. Patwardhan AM, Scotland PE, Akopian AN, Hargreaves KM: Activation of TRPV1 in the spinal cord by oxidized linoleic acid metabolites contributes to inflammatory hyperalgesia. Proc Natl Acad Sci U S A 2009, 106:18820-18824

26. Feldstein AE, Lopez R, Tamimi TA, Yerian L, Chung YM, Berk M, Zhang R, McIntyre TM, Hazen SL: Mass spectrometric profiling of oxidized lipid products in human nonalcoholic fatty liver disease and nonalcoholic steatohepatitis. J Lipid Res 2010, 51:3046-3054

27. Zein CO, Yerian LM, Gogate P, Lopez R, Kirwan JP, Feldstein AE, McCullough AJ: Pentoxifylline improves nonalcoholic steatohepatitis: a randomized placebo-controlled trial. Hepatology 2011, 54: $1610-1619$

28. Raszeja-Wyszomirska J, Safranow K, Milkiewicz M, Milkiewicz P, Szynkowska A, Stachowska E: Lipidic last breath of life in patients with alcoholic liver disease. Prostaglandins Other Lipid Mediat 2012, 99:51-56

29. Yang L, Latchoumycandane C, McMullen MR, Pratt BT, Zhang R, Papouchado BG, Nagy LE, Feldstein AE, McIntyre TM: Chronic alcohol exposure increases circulating bioactive oxidized phospholipids. J Biol Chem 2010, 285:22211-22220

30. Liu H, Beier JI, Arteel GE, Ramsden CE, Feldstein AE, McClain CJ, Kirpich IA: Transient receptor potential vanilloid 1 gene deficiency ameliorates hepatic injury in a mouse model of chronic binge alcoholinduced alcoholic liver disease. Am J Pathol 2015, 185:43-54

31. Bertola A, Mathews S, Ki SH, Wang H, Gao B: Mouse model of chronic and binge ethanol feeding (the NIAAA model). Nat Protoc 2013, 8:627-637

32. Takahashi $\mathrm{T}$, Kamimura $\mathrm{T}$, Ichida F: Ultrastructural findings on polymorphonuclear leucocyte infiltration and acute hepatocellular damage in alcoholic hepatitis. Liver 1987, 7:347-358

33. Kirpich IA, Feng W, Wang Y, Liu Y, Beier JI, Arteel GE, Falkner KC, Barve SS, McClain CJ: Ethanol and dietary unsaturated fat (corn oil/linoleic acid enriched) cause intestinal inflammation and impaired intestinal barrier defense in mice chronically fed alcohol. Alcohol 2013, 47:257-264

34. Kirpich IA, Gobejishvili LN, Bon Homme M, Waigel S, Cave M, Arteel G, Barve SS, McClain CJ, Deaciuc IV: Integrated hepatic transcriptome and proteome analysis of mice with high-fat dietinduced nonalcoholic fatty liver disease. J Nutr Biochem 2011, 22 $38-45$

35. Livak KJ, Schmittgen TD: Analysis of relative gene expression data using real-time quantitative PCR and the 2(-Delta Delta $\mathrm{C}(\mathrm{T})$ ) Method. Methods 2001, 25:402-408

36. Maddipati KR, Zhou SL: Stability and analysis of eicosanoids and docosanoids in tissue culture media. Prostaglandins Other Lipid Mediat 2011, 94:59-72

37. Maddipati KR, Romero R, Chaiworapongsa T, Zhou SL, Xu Z, Tarca AL, Kusanovic JP, Munoz H, Honn KV: Eicosanomic profiling reveals dominance of the epoxygenase pathway in human amniotic fluid at term in spontaneous labor. FASEB J 2014, 28: $4835-4846$

38. Maddipati KR, Romero R, Chaiworapongsa T, Chaemsaithong P, Zhou S-L, Xu Z, Tarca AL, Kusanovic JP, Gomez R, Chaiyasit N, Honn KV: Lipidomic analysis of patients with microbial invasion of the amniotic cavity reveals up-regulation of leukotriene B4. FASEB J 2016, 30:3296-3307

39. Maddipati KR, Romero R, Chaiworapongsa T, Chaemsaithong P, Zhou S-L, Xu Z, Tarca AL, Kusanovic JP, Gomez R, Docheva N, Honn KV: Clinical chorioamnionitis at term: the amniotic fluid fatty acyl lipidome. J Lipid Res 2016, 57:1906-1916

40. Zein CO, Lopez R, Fu X, Kirwan JP, Yerian LM, McCullough AJ, Hazen SL, Feldstein AE: Pentoxifylline decreases oxidized lipid products in nonalcoholic steatohepatitis: new evidence on the potential therapeutic mechanism. Hepatology 2012, 56:1291-1299

41. Ge X, Antoine DJ, Lu Y, Arriazu E, Leung TM, Klepper AL, Branch AD, Fiel MI, Nieto N: High mobility group box-1 (HMGB1) participates in the pathogenesis of alcoholic liver disease (ALD). J Biol Chem 2014, 289:22672-22691

42. Kolaczkowska E, Kubes P: Neutrophil recruitment and function in health and inflammation. Nat Rev Immunol 2013, 13:159-175

43. Pham CT: Neutrophil serine proteases: specific regulators of inflammation. Nat Rev Immunol 2006, 6:541-550 
44. Ramaiah SK, Jaeschke H: Hepatic neutrophil infiltration in the pathogenesis of alcohol-induced liver injury. Toxicol Mech Methods 2007, 17:431-440

45. Bertola A, Park O, Gao B: Chronic plus binge ethanol feeding synergistically induces neutrophil infiltration and liver injury in mice: a critical role for E-selectin. Hepatology 2013, 58:1814-1823

46. Nanji AA, Jokelainen K, Tipoe GL, Rahemtulla A, Dannenberg AJ: Dietary saturated fatty acids reverse inflammatory and fibrotic changes in rat liver despite continued ethanol administration. J Pharmacol Exp Ther 2001, 299:638-644

47. Kono H, Enomoto N, Connor HD, Wheeler MD, Bradford BU, Rivera CA, Kadiiska MB, Mason RP, Thurman RG: Medium-chain triglycerides inhibit free radical formation and TNF-alpha production in rats given enteral ethanol. Am J Physiol Gastrointest Liver Physiol 2000, 278:G467-G476

48. Fulham MA, Mandrekar P: Sexual dimorphism in alcohol induced adipose inflammation relates to liver injury. PLoS One 2016, 11 : e0164225

49. Ambade A, Catalano D, Lim A, Kopoyan A, Shaffer SA, Mandrekar P: Inhibition of heat shock protein 90 alleviates steatosis and macrophage activation in murine alcoholic liver injury. J Hepatol 2014, 61:903-911

50. Itoh T, Fairall L, Amin K, Inaba Y, Szanto A, Balint BL, Nagy L, Yamamoto K, Schwabe JW: Structural basis for the activation of PPARgamma by oxidized fatty acids. Nat Struct Mol Biol 2008, 15: 924-931

51. Chen CW, Lee ST, Wu WT, Fu WM, Ho FM, Lin WW: Signal transduction for inhibition of inducible nitric oxide synthase and cyclooxygenase- 2 induction by capsaicin and related analogs in macrophages. Br J Pharmacol 2003, 140:1077-1087

52. Ricote M, Li AC, Willson TM, Kelly CJ, Glass CK: The peroxisome proliferator-activated receptor-gamma is a negative regulator of macrophage activation. Nature 1998, 391:79-82

53. Rikitake Y, Hirata K, Yamashita T, Iwai K, Kobayashi S, Itoh H, Ozaki M, Ejiri J, Shiomi M, Inoue N, Kawashima S, Yokoyama M: Expression of G2A, a receptor for lysophosphatidylcholine, by macrophages in murine, rabbit, and human atherosclerotic plaques. Arterioscler Thromb Vasc Biol 2002, 22:2049-2053

54. Fajas L, Auboeuf D, Raspe E, Schoonjans K, Lefebvre AM, Saladin R, Najib J, Laville M, Fruchart JC, Deeb S, Vidal-Puig A, Flier J, Briggs MR, Staels B, Vidal H, Auwerx J: The organization, promoter analysis, and expression of the human PPARgamma gene. J Biol Chem 1997, 272:18779-18789

55. Warden A, Truitt J, Merriman M, Ponomareva O, Jameson K, Ferguson LB, Mayfield RD, Harris RA: Localization of PPAR isotypes in the adult mouse and human brain. Sci Rep 2016, 6:27618

56. Li Q, Li L, Wang F, Chen J, Zhao Y, Wang P, Nilius B, Liu D, Zhu Z: Dietary capsaicin prevents nonalcoholic fatty liver disease through transient receptor potential vanilloid 1-mediated peroxisome proliferator-activated receptor delta activation. Pflugers Arch 2013, 465:1303-1316

57. Menigoz A, Boudes M: The expression pattern of TRPV1 in brain. J Neurosci 2011, 31:13025-13027
58. Sears DD, Miles PD, Chapman J, Ofrecio JM, Almazan F, Thapar D, Miller YI: 12/15-Lipoxygenase is required for the early onset of high fat diet-induced adipose tissue inflammation and insulin resistance in mice. PLoS One 2009, 4:e7250

59. Nunemaker CS, Chen M, Pei H, Kimble SD, Keller SR, Carter JD, Yang Z, Smith KM, Wu R, Bevard MH, Garmey JC, Nadler JL: 12Lipoxygenase-knockout mice are resistant to inflammatory effects of obesity induced by Western diet. Am J Physiol Endocrinol Metab 2008, 295:E1065-E1075

60. Martinez-Clemente M, Ferre N, Titos E, Horrillo R, GonzalezPeriz A, Moran-Salvador E, Lopez-Vicario C, Miquel R, Arroyo V, Funk CD, Claria J: Disruption of the 12/15-lipoxygenase gene (Alox15) protects hyperlipidemic mice from nonalcoholic fatty liver disease. Hepatology 2010, 52:1980-1991

61. Lazic $\mathrm{M}$, Inzaugarat $\mathrm{ME}$, Povero $\mathrm{D}$, Zhao IC, Chen $\mathrm{M}$, Nalbandian M, Miller YI, Chernavsky AC, Feldstein AE, Sears DD: Reduced dietary omega- 6 to omega-3 fatty acid ratio and 12/15lipoxygenase deficiency are protective against chronic high fat dietinduced steatohepatitis. PLoS One 2014, 9:e107658

62. Ruparel S, Hargreaves KM, Eskander M, Rowan S, de Almeida JF, Roman L, Henry MA: Oxidized linoleic acid metabolitecytochrome P450 system (OLAM-CYP) is active in biopsy samples from patients with inflammatory dental pain. Pain 2013, 154: $2363-2371$

63. Ruparel S, Green D, Chen P, Hargreaves KM: The cytochrome P450 inhibitor, ketoconazole, inhibits oxidized linoleic acid metabolitemediated peripheral inflammatory pain. Mol Pain 2012, 8:73

64. Wen Y, Gu J, Vandenhoff GE, Liu X, Nadler JL: Role of 12/15lipoxygenase in the expression of $\mathrm{MCP}-1$ in mouse macrophages. Am J Physiol Heart Circ Physiol 2008, 294:H1933-H1938

65. Wen Y, Gu J, Chakrabarti SK, Aylor K, Marshall J, Takahashi Y, Yoshimoto T, Nadler JL: The role of 12/15-lipoxygenase in the expression of interleukin- 6 and tumor necrosis factor-alpha in macrophages. Endocrinology 2007, 148:1313-1322

66. Saiwai H, Ohkawa Y, Yamada H, Kumamaru H, Harada A, Okano H, Yokomizo T, Iwamoto Y, Okada S: The LTB4-BLT1 axis mediates neutrophil infiltration and secondary injury in experimental spinal cord injury. Am J Pathol 2010, 176:2352-2366

67. Cheng Y, Zhao J, Tse HF, Le XC, Rong J: Plant natural products calycosin and gallic acid synergistically attenuate neutrophil infiltration and subsequent injury in isoproterenol-induced myocardial infarction: a possible role for leukotriene B4 12hydroxydehydrogenase? Oxid Med Cell Longev 2015, 2015:434052

68. Admyre C, Axelsson LG, von Stein O, Zargari A: Immunomodulatory oligonucleotides inhibit neutrophil migration by decreasing the surface expression of interleukin-8 and leukotriene B4 receptors. Immunology 2015, 144:206-217

69. Uderhardt S, Kronke G: 12/15-Lipoxygenase during the regulation of inflammation, immunity, and self-tolerance. J Mol Med 2012, 90: $1247-1256$

70. Vangaveti V, Baune BT, Kennedy RL: Hydroxyoctadecadienoic acids: novel regulators of macrophage differentiation and atherogenesis. Ther Adv Endocrinol Metab 2010, 1:51-60 